\title{
Texture and Mechanical Anisotropy of Ultrafine-Grained Aluminum Alloy AA6016 Produced by Accumulative Roll Bonding
}

\author{
Werner Skrotzki, ${ }^{1}$ Ingwar Hünsche, ${ }^{1}$ Juliane Hüttenrauch, ${ }^{1}$ C.-G. Oertel, ${ }^{1}$ Heinz-Günter Brokmeier, ${ }^{2}$ \\ Heinz Werner Höppel, ${ }^{3}$ and Irena Topic ${ }^{3}$ \\ ${ }^{1}$ Institut für Strukturphysik, Technische Universität Dresden, 01062 Dresden, Germany \\ ${ }^{2}$ GKSS Forschungszentrum, Max-Planck-Straße, 21494 Geesthacht, Germany \\ ${ }^{3}$ Lehrstuhl Allgemeine Werkstoffeigenschaften, Universität Erlangen-Nürnberg, Martensstraße 5, 91058 Erlangen, Germany
}

Correspondence should be addressed to Werner Skrotzki, werner.strotzki@physik.tu-dresden.de

Received 22 June 2007; Accepted 6 December 2007

Recommended by Claude Esling

The texture of ultrafine-grained Al alloy AA6016 produced by accumulative roll bonding (ARB) has been measured by neutron diffraction. The starting texture consists of a strong cube component. During ARB, this texture breaks down and a texture typical for rolling of face-centered cubic metals with high stacking fault energy develops. The texture after 8 ARB cycles is characterised by the $\beta$-fiber with the $\mathrm{Cu}$ component dominating. Moreover, the rotated cube component is formed. This component is typical for simple shear, which takes place during rolling on the surfaces of the sheets. Based on the Taylor factor and calculated Lankford parameter, the mechanical anisotropy of the advanced metal sheets is discussed.

Copyright (C) 2008 Werner Skrotzki et al. This is an open access article distributed under the Creative Commons Attribution License, which permits unrestricted use, distribution, and reproduction in any medium, provided the original work is properly cited.

\section{INTRODUCTION}

During recent years, bulk ultrafine-grained (UFG) materials, produced by severe plastic deformation (SPD) and with grain sizes in the range of $1 \mu \mathrm{m}$ down to $100 \mathrm{~nm}$, have received considerable scientific attention (e.g., [1]). Compared to their conventional grain-sized counterparts, the UFG microstructure leads, beside many other enhanced properties in UFG materials, to an extraordinary highstrength and enhanced ductility [2]. From the technical point of view, ARB is a highly promising process because it incorporates the production of new UFG materials and because it can be easily integrated into existing industrial process chains. Due to their significantly higher specific strength, UFG materials have a high light-weight construction potential for automobile and aircraft industry, while their enhanced ductility may contribute to good metal sheet formability using conventional techniques such as bulge testing or deep drawing. As high strength and light weight structural components, the use of UFG mate- rials can lead to weight reduction and resource conservation.

While much is known about texture formation in SPD materials produced by equal channel angular pressing (e.g., [3]), texture measurements on face-centered cubic (FCC) metals subjected to accumulative roll bonding (ARB) are less frequent. ARB, which was originally introduced by Saito et al. (Figure 1), is a process where the rolled sheet is cut, polished, brushed, stacked, and then roll bonded [4-6]. By repeating this procedure, very high strains can be introduced sucessfully into different metals and alloys, and as a result, significant structural refinement can be achieved. Observations of the structural evolution during ARB have shown the formation of a lamellar structure at high strains, indicating a similarity to what takes place during conventional rolling [7]. Furthermore, texture formation should be comparable with that of the conventional rolling. However, because of repeated stacking of sheets containing a texture gradient characterized by plane strain deformation in the centre and a high portion of shear in the surface layer of the sheets, marked 


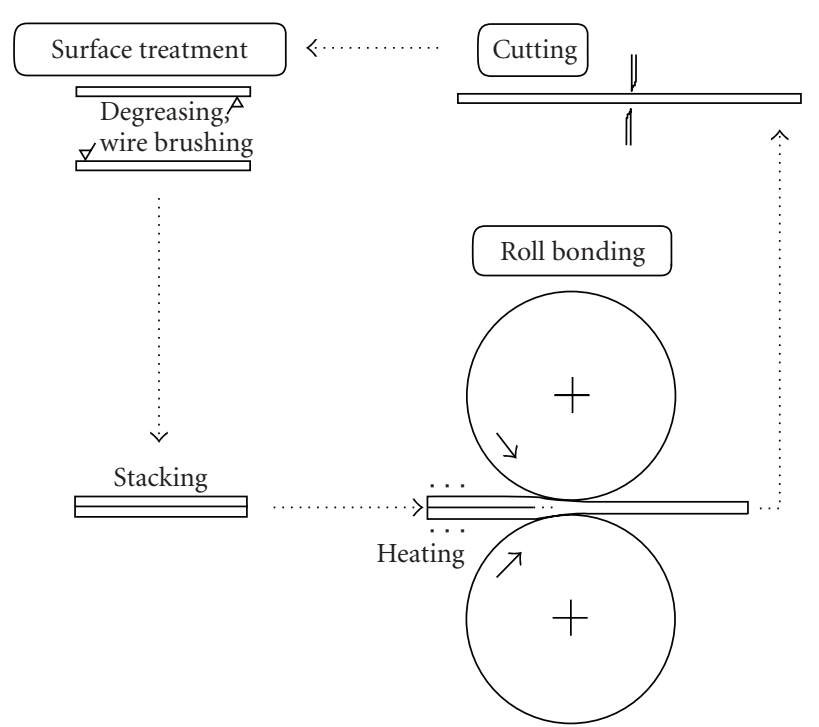

Figure 1: Principle of the accumulative roll bonding process [4].

differences are expected. Moreover, there are small zones heavily treated by brushing in order to accomplish a good bonding.

The present project aims at studying the formation of texture thoroughly in AA6016 as a function of ARB cycles. This alloy is often used in the automotive industry for body panels. Therefore, based on the Taylor factor and the calculated Lankford parameter, the mechanical anisotropy of the advanced metal sheets is discussed.

\section{EXPERIMENTAL DETAILS}

In this investigation, sheets of the aluminum alloy AA6016 with an original thickness of $1 \mathrm{~mm}$ were used. The chemical composition is listed in Table 1. Prior to roll bonding, the material was a solution, heat treated at $520^{\circ} \mathrm{C}$ for 1 hour and subsequently quenched in water. Prior to rolling, the sheets were prewarmed in a furnace to $230^{\circ} \mathrm{C}$ for $4 \mathrm{~min}$ utes. The ARB process, optimized with regard to thermal stability and interlamellar bonding [6], was applied using a four-high rolling mill (Carl Wezel, Mühlacker) at a workpiece temperature of $230^{\circ} \mathrm{C}$ to small strips of material, which had a width of $80-100 \mathrm{~mm}$ and a length of approximately $300 \mathrm{~mm}$. The thickness reduction was set nominally to $50 \%$ per rolling pass. After each pass (cycle), the surfaces were wire brushed in order to remove the oxide layer and the sheet was folded at half of the length and then the rolling process was repeated (Figure 1). A maximum of 8 ARB cycles, corresponding to $\varepsilon_{\text {von Mises }}=6.4$, were applied which lead to a sheet with $2^{8}=256$ bonded layers, each having a thickness of $3.9 \mu \mathrm{m}$. After each cycle, the bonded metal sheets were air cooled.

The microstructure of the ARB processed AA6016 after different number of cycles was observed using scanning and transmission electron microscopy (SEM: Zeiss
DSM 965, TEM: Philips CM 200). Sheet cross-sections for SEM observation and TEM foils after mechanical grinding were prepared using the standard Struers electrolyte A2 at $20 \mathrm{~V}$ at about $-10^{\circ} \mathrm{C}$ and $22 \mathrm{~V}$ at room temperature, respectively.

Texture measurements were done by neutron diffraction on a stack of eight sheets with a size of $10 \mathrm{~mm} \times 10 \mathrm{~mm}$. Because of their high penetration depth, neutrons allow bulk texture measurements. The orientation distribution function (ODF) was calculated from the measured pole figures (200, $220,111)$ by using the harmonic method with a maximum series expansion coefficient of $22[8,9]$. The Euler angles are in the Bunge notation [10].

To discuss the texture-induced plastic anisotropy, the Taylor-Bishop-Hill theory of crystal plasticity was used to calculate the Taylor factor and the Lankford parameter [1113]. The Taylor factor $M$ describes the correlation between applied stress $\sigma_{x x}$ and resolved shear stress $\tau$ according to

$$
M=\frac{\sigma_{x x}}{\tau}
$$

with $x$ being parallel to the tensile axis. In polycrystalline metals, the Taylor factor of the aggregate is a superposition of the Taylor factors of each orientation $M_{i}$ weighted by its volume fraction $f_{i}$ :

$$
M_{\mathrm{res}}=\sum_{i} f_{i} M_{i}
$$

To calculate $M$, the Taylor Program written by Van Houtte [14] was used. For room temperature deformation, the $\{111\}\langle 110\rangle$ slip systems were taken.

For discussion of the yield stress, it is necessary to examine $M$ as a function of the Lankford parameter

$$
r=\frac{d \varepsilon_{y y}}{d \varepsilon_{z z}},
$$

where $d \varepsilon_{y y}$ and $d \varepsilon_{z z}$ are incremental strains in $y$ and $z$ directions, that is, within and normal to the sheet plane, respectively. For plane strain deformation with $d \varepsilon_{z z}=0, r$ becomes infinite. Therefore, it is more appropriate to use $\rho$ describing the ratio of width contraction to tensile extension:

$$
\rho=\frac{-d \varepsilon_{y y}}{d \varepsilon_{x x}}
$$

Assuming volume constancy $\left(d \varepsilon_{x x}+d \varepsilon_{y y}+d \varepsilon_{z z}=0\right)$ the Lankford parameter becomes

$$
r=\frac{\rho}{1-\rho}
$$

Minima in the $M(\rho)$ curves belonging to minimum Taylor energy give information on the most likely deformation mode during tension [15-19]. Thus $\rho$ at minimum $M$ yields $r$. To get information on the deep drawing properties of 


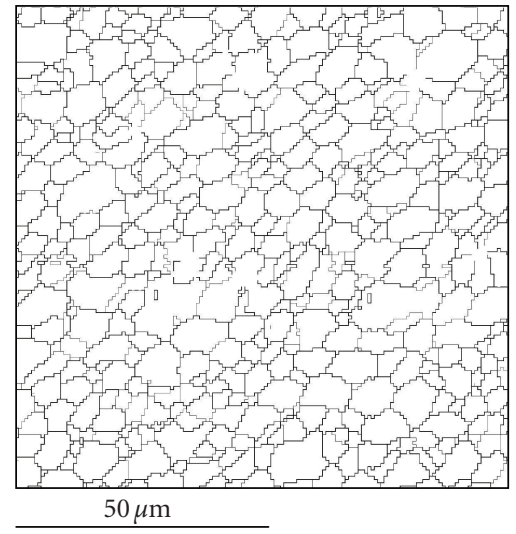

(a)

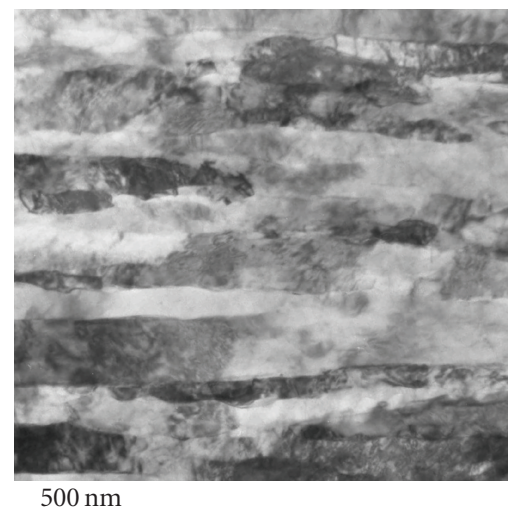

(c)

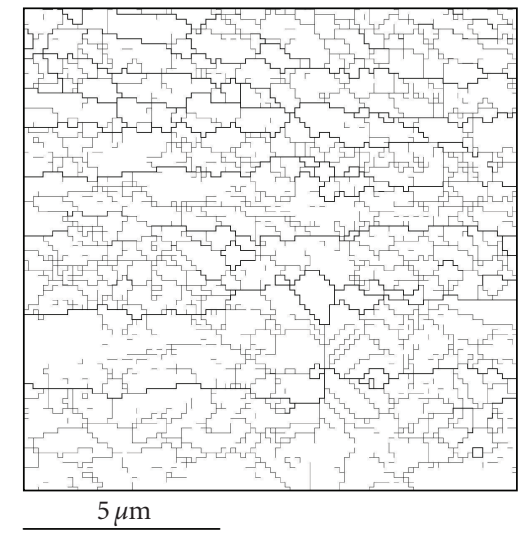

(b)

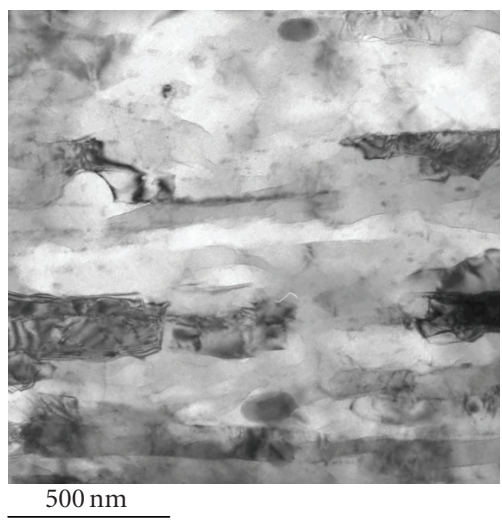

(d)

FIGURE 2: SEM image of the grain structure in the initial state (a) and after 2 ARB cycles (b) (reconstructed from an orientation map) with low- and high-angle boundaries shown as thin and thick lines, respectively. TEM bright-field images of the lamellar subgrain and grain structure after 4 (c) and 8 ARB cycles (d), respectively. (Horizontal: rolling direction RD, vertical: normal direction ND.)

TABLE 1: Chemical composition of aluminum alloy AA6016.

\begin{tabular}{lcccccccccc}
\hline wt.\% & $\mathrm{Si}$ & $\mathrm{Cu}$ & $\mathrm{Fe}$ & $\mathrm{Mn}$ & $\mathrm{Mg}$ & $\mathrm{Cr}$ & $\mathrm{Zn}$ & $\mathrm{Ti}$ & $\mathrm{Other}$ & $\mathrm{Al}$ \\
\hline AA6016 & $1.0-1.5$ & 0.52 & 0.5 & 0.2 & $0.25-0.6$ & 0.1 & 0.2 & 0.15 & 0.15 & Balance \\
\hline
\end{tabular}

rolled sheets, the coefficient of normal anisotropy

$$
\langle r\rangle=\frac{1}{4}\left(r_{\mathrm{RD}}+2 r_{45^{\circ}}+r_{\mathrm{TD}}\right)
$$

and its variation

$$
\Delta r=\frac{1}{2}\left(r_{\mathrm{RD}}-2 r_{45^{\circ}}+r_{\mathrm{TD}}\right)
$$

(with $\mathrm{RD}=$ rolling direction, $\mathrm{TD}=$ transverse direction, and $45^{\circ}=$ direction at $45^{\circ}$ to $\mathrm{RD}$ in the rolling plane) are important. For good deep drawing, $\langle r\rangle$ should be large, thus only leading to a small thickness reduction, and $\Delta r$ should be zero leading to isotropic drawing conditions within the sheet plane.

\section{RESULTS AND DISCUSSION}

The starting material is totally recrystallized with equiaxed grains with sizes of about $20-30 \mu \mathrm{m}$ (Figure 2(a)). During $\mathrm{ARB}$, an ultrafine-grained lamellar structure develops (Figure 2(b)). After 3-4 cycles, a steady-state width of the lamellae of about $200 \mathrm{~nm}$ is reached (Figures 2(c), 2(d)) [6]. 


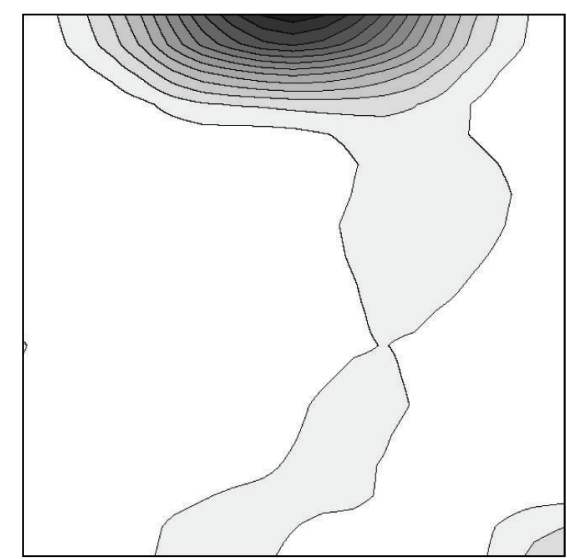

(a) 0 cycles, max: 14.6 m.r.d.

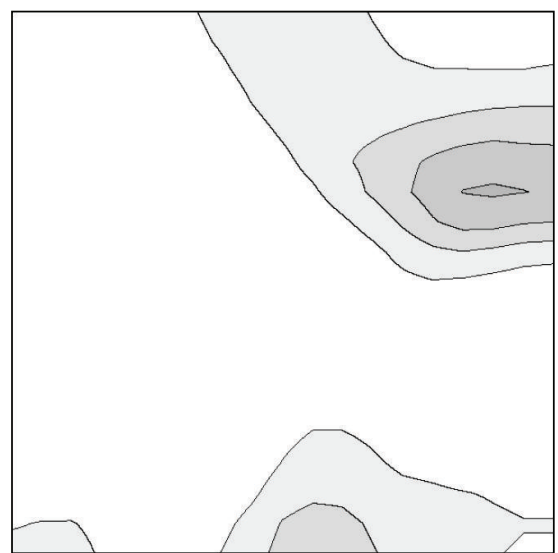

(b) 2 cycles, max: 4.4 m.r.d.

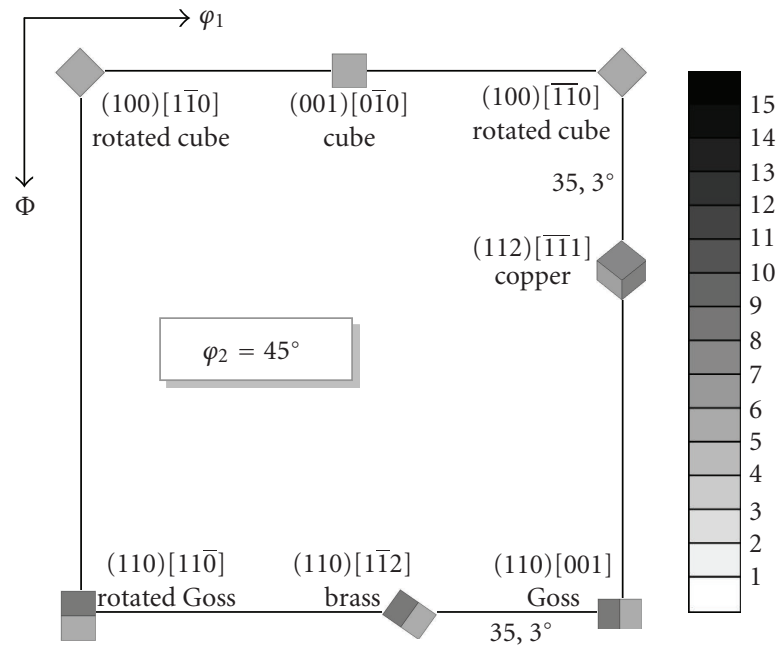

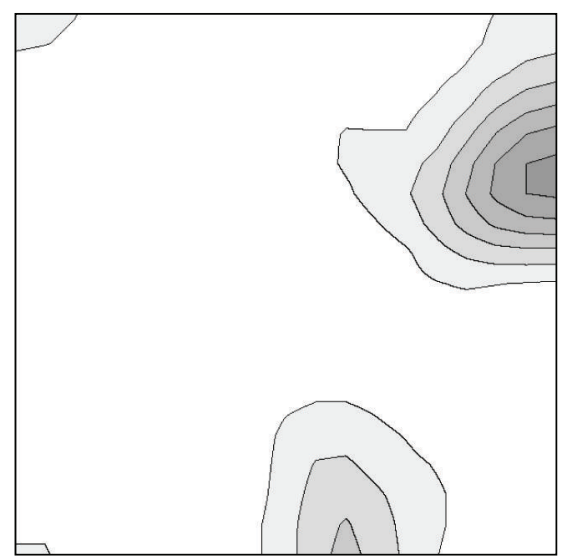

(c) 4 cycles, max: 6.7 m.r.d.

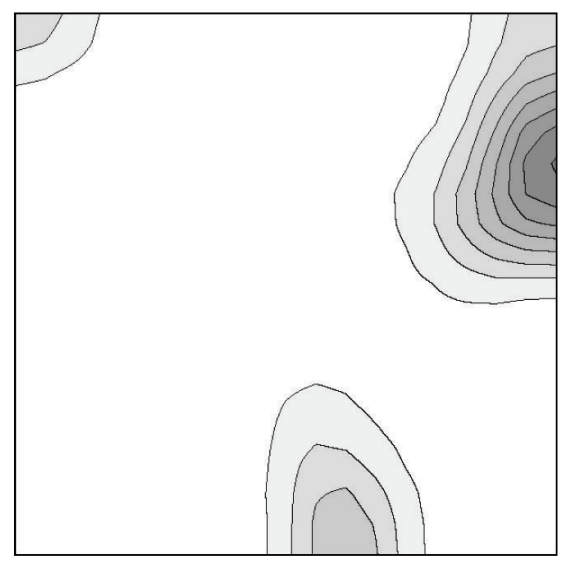

(d) 6 cycles, max: 8.7 m.r.d.

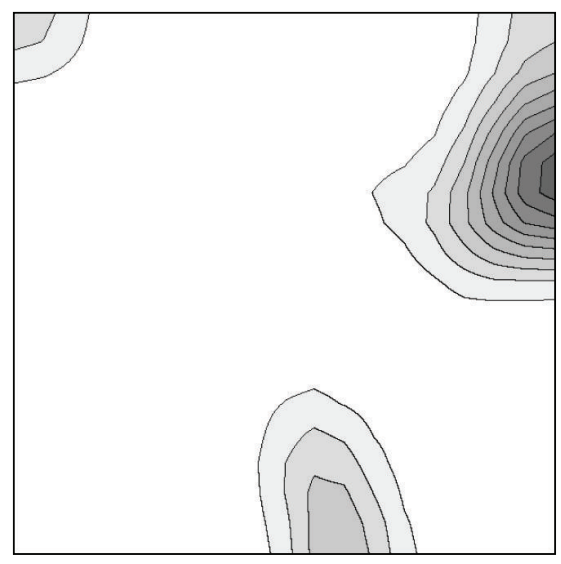

(e) 8 cycles, max: 10.1 m.r.d.

Figure 3: Texture of ARB AA6016 after (a) 0, (b) 2, (c) 4, (d) 6, and (e) 8 cycles displayed as ODF sections at $\varphi_{2}=45^{\circ}$ with intensities given in multiples of a random distribution (m.r.d.). Key figure shows the position of the main texture components. 


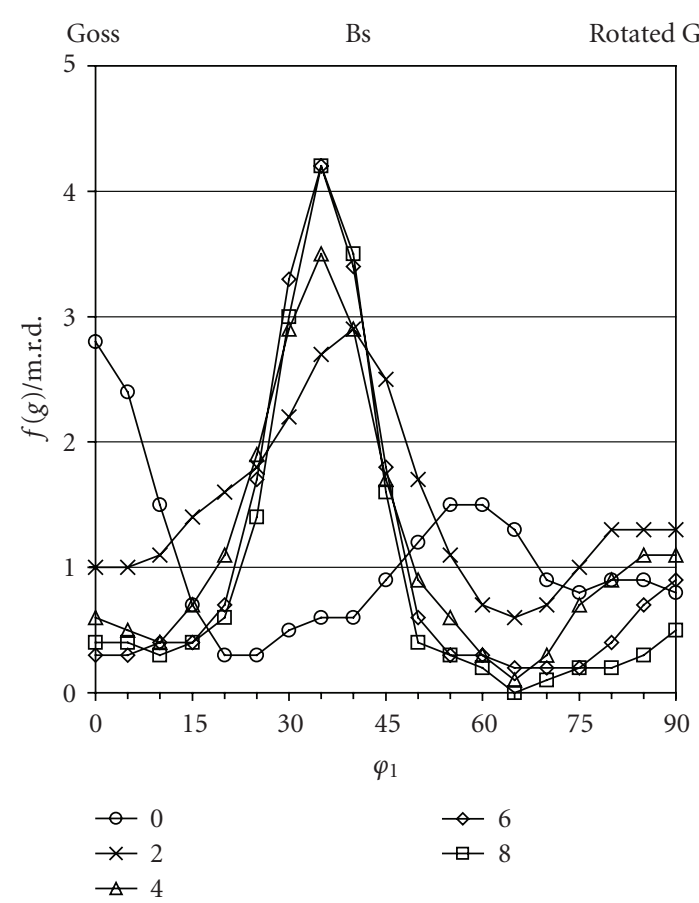

(a)

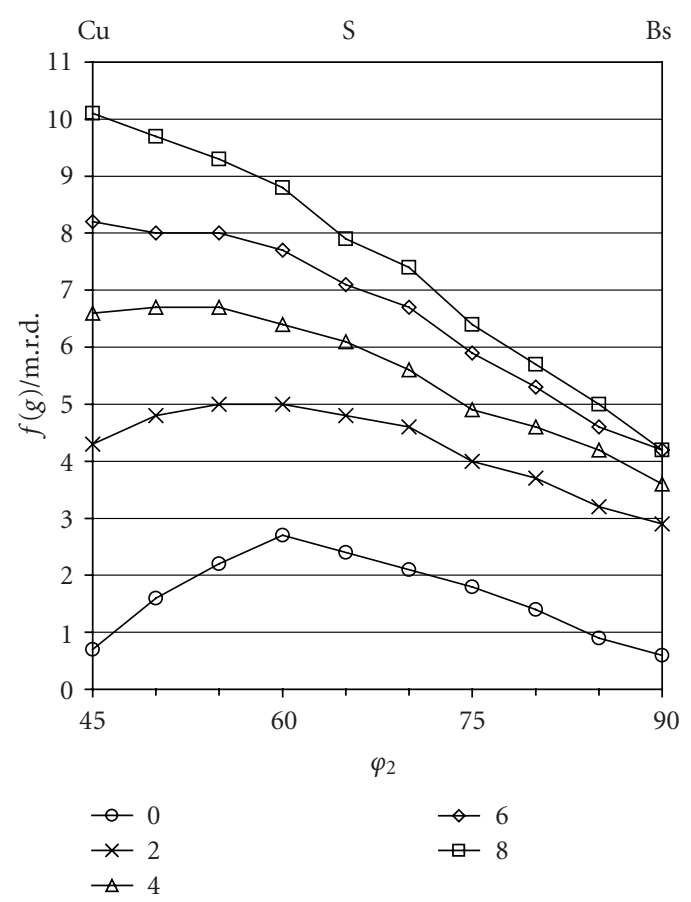

(b)

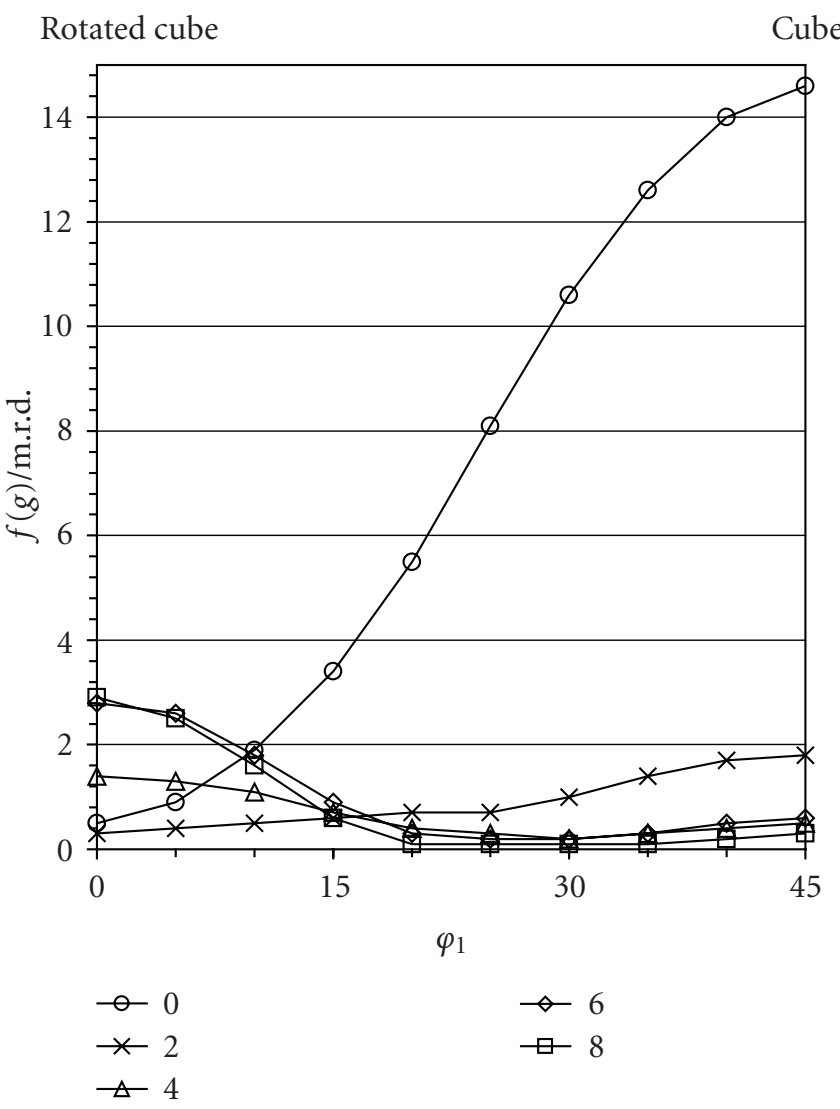

(c)

Figure 4: Intensity along different fibers: (a) $\alpha$-fiber, (b) $\beta$-fiber, and (c) ND-fiber. 


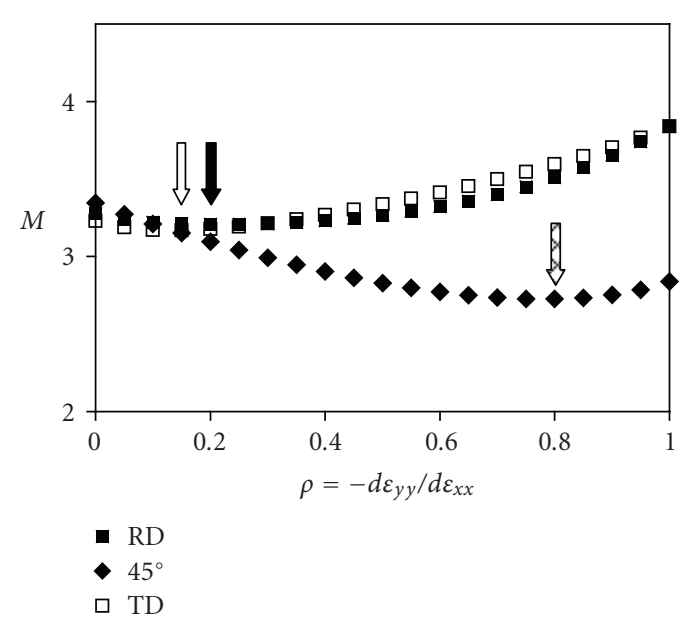

FIGURE 5: Taylor factor $M$ calculated with the FC Taylor model as a function of strain mode for tensile deformation of an ARB sheet (8 cycles) in different directions. Arrows mark the minima in the $M(\rho)$ curves.

A more detailed analysis of the microstructural evolution by electron backscatter diffraction (EBSD) is under way.

The starting texture consists of a strong cube component, spreading out to form a $\langle 100\rangle$ fiber parallel to ND and a minor Goss component (Figures 3, 4(a), and 4(c)). During ARB, this texture breaks down and a texture typical for rolling of face-centered cubic (FCC) metals with high-stacking fault energy develops. The texture is characterised by the $\beta$-fiber with the $\mathrm{Cu}$ component dominating (Figures 3 and $4(\mathrm{~b})$ ). Moreover, the rotated cube component is formed. This component typical of simple shear during rolling develops in the surface layer of the sheets. The shown textures are the bulk textures of the entire sheet thickness. Thus, with these textures, it is possible to calculate the bulk properties of the ARB sheets. Calculations of the mechanical anisotropy of the sheets are given in Figure 3.

The calculations using the Taylor model were done with a systematic variation of the strain tensor $[19,20]$. The variation of the strain tensor describes different deformation modes (e.g., $\rho=0$ and 1; plane strain, $\rho=0.5$ : axially symmetric deformation) which are directly related to the Lankford parameter (see (3)). The textures measured for each sheet were discretized into 1000 single orientations. The denoted Taylor factors $M$ are the volume weighted means of the $M_{i}$ factors calculated for these sheet orientations (see (2)). The minimum $M$ value characterises the minimum deformation energy and the deformation mode is given by $\rho$ at minimum $M$ (Figure 5). The Taylor calculations were done with the full and relaxed constraints (FC and RC) models. Strong rolling leads to flattening of grains in the rolling plane and elongation in the $\mathrm{RD}$. Therefore, in case of RC, the so-called pancake model was used, that is, the shear strains, $\varepsilon_{z x}$ and $\varepsilon_{z y}$, in the rolling plane were relaxed.

Figure 6 shows the Taylor factor as a function of the number of cycles. In the initial state (cube recrystallisation tex- ture), $M_{45^{\circ}}$ is higher than $M_{\mathrm{RD}}$ and $M_{\mathrm{TD}}$. After ARB cycling, giving rise to the typical FCC rolling texture development, this relation is reversed. The $M$ values calculated with the FC Taylor model are somewhat higher than those calculated with the RC model. Moreover, in the RC case $M_{\mathrm{TD}}$ is slightly smaller than $M_{\mathrm{RD}}$. As $M$ is directly related to the flow stress (1) there is flow stress anisotropy between $\mathrm{RD} / \mathrm{TD}$ and $45^{\circ}$, which becomes reversed with ARB cycling.

Figure 7 shows the Lankford parameter as a function of the number of cycles. Similar to the anisotropy of $M$, in the initial state, $r_{\mathrm{RD}}$ and $r_{\mathrm{TD}}$ are higher than $r_{45^{\circ}}$. After ARB, this relation is reversed. As $r$ is related to $\rho$ (3) this means that with $\mathrm{ARB}$ cycling the strain mode during tension changes. The results obtained with the FC and RC models are in qualitative agreement. A strong increase of simulated $r_{45} 5^{\circ}$ values with rolling degree has also been reported by Park [21]. However, in this case a strong discrepancy with experiment exists.

The deep drawing conditions of the sheets can be judged from the magnitudes of $\langle r\rangle$ and $\Delta r$.

The larger the $\langle r\rangle$, the less the sheet thinning takes place, while a decrease of the norm of $\Delta r$ leads to less earing.

As seen in Figure 8, $\langle r\rangle$ increases steadily with increasing the number of cycles, while $\Delta r$ decreases and changes its sign. Thus with regard to sheet thinning, the high-cycle ARB state is best suited. In contrast, the low-cycle ARB state should not result in any earing. As $\Delta r$ changes its sign with increasing the number of $\mathrm{ARB}$ cycles, earing is shifted from the $\mathrm{RD} / \mathrm{TD}$ positions ( $\Delta r$ positive) in the initial state to the $45^{\circ}$ positions $(\Delta r$ negative) in the high-cycle ARB state.

In conclusion, the results obtained here reveal that lowcycle ARB material may be optimal for deep drawing, while they also show good strength and ductility. Although highcycle ARB leads to higher strength and ductility [6], desirable drawing properties are not expected due to earing. It should be pointed out that the considerations made above are based on standard room temperature deformation mechanisms. As discussed in literature, high temperature deformation mechanisms like grain boundary sliding, coble creep, and thermally activated annihilation of dislocations should be considered for UFG aluminium materials even at low homologous temperatures [2, 22, 23]. From the above-made considerations, it is suggested that for obtaining a good compromise between strength and deep drawing ability, the sheets should be rolled between 3 to 5 ARB cycles. In this context, it should be also mentioned that recent results on ARB processed AA6016 alloy (up to 8 cycles) show very promising formability under the complex loading conditions in a bulge test. The observed formability of UFG AA6016 is comparable to the conventional grain-sized counterparts, but the UFG material exhibits higher burst pressures [24]. However, in comparison to bulge testing slightly different material behavior may be expected during deep drawing due to a different stress state.

Nevertheless, starting with a cube texture low-cycle ARB may be optimal for deep drawing with simultaneously fulfilling good strength and ductility. Measurements of the Lankford parameter confirming the calculations presented 


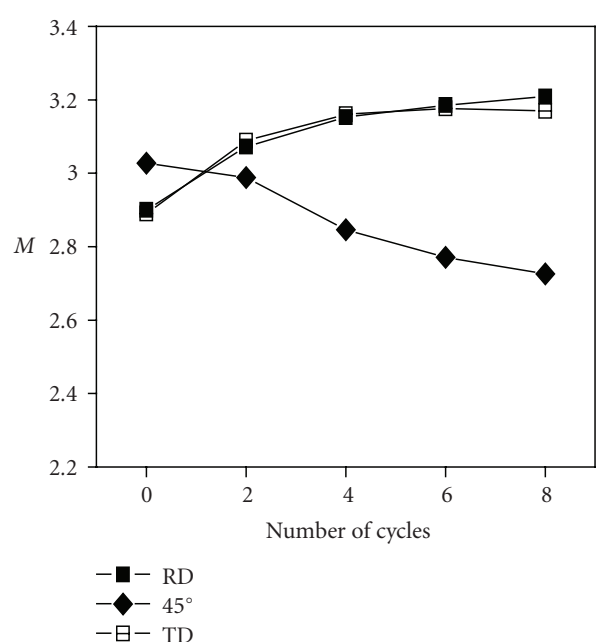

(a)

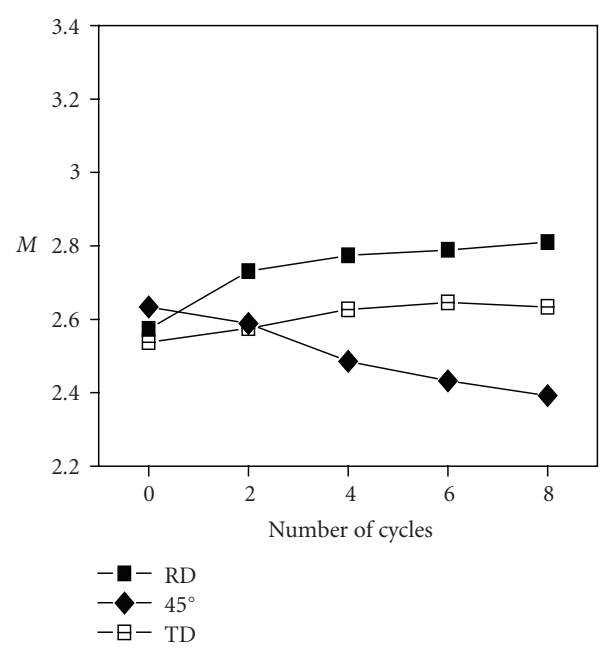

(b)

FIGURE 6: Taylor factor $M$ at minimum $\rho$ as a function of the number of cycles, (a) FC and (b) RC Taylor models.

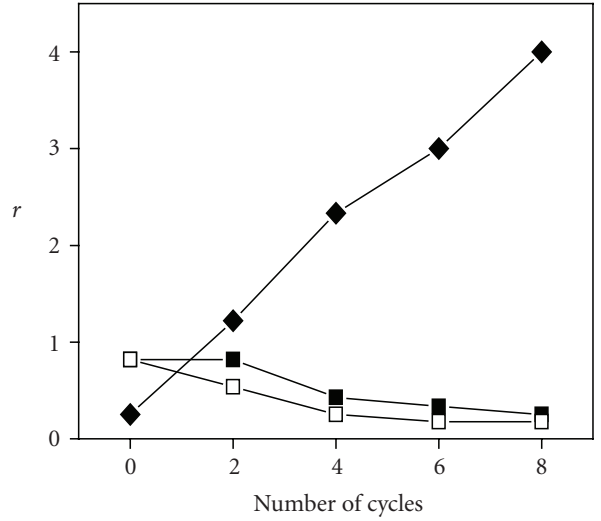

$$
\begin{aligned}
& -\mathrm{mD} \\
& -\boldsymbol{-}-45^{\circ} \\
& -\square-\mathrm{TD}
\end{aligned}
$$

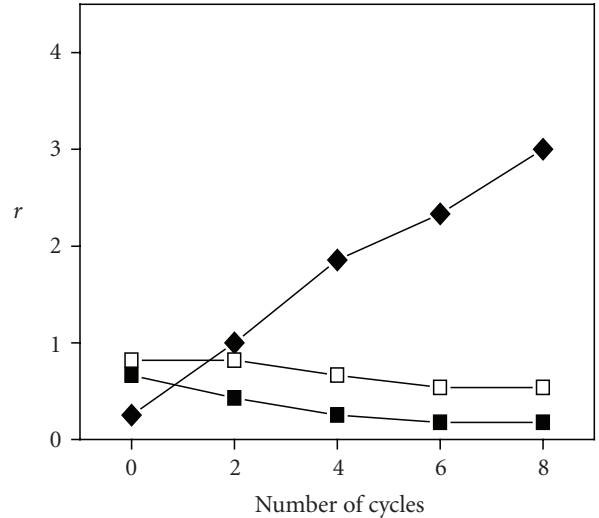

$-\mathrm{RD}$
$-\boldsymbol{-}-45^{\circ}$
$-\mathrm{D}-\mathrm{TD}$

(a)

(b)

FIGURE 7: Lankford parameter $r$ calculated for tensile deformation in different directions as a function of the number of cycles, (a) FC and (b) RC Taylor models.

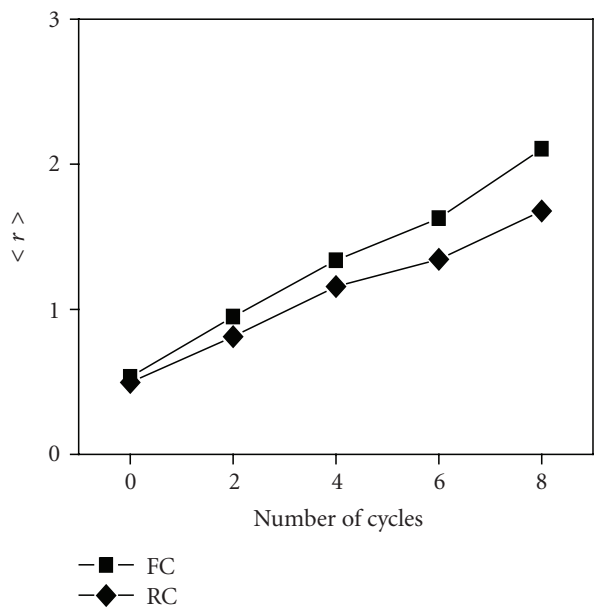

(a)

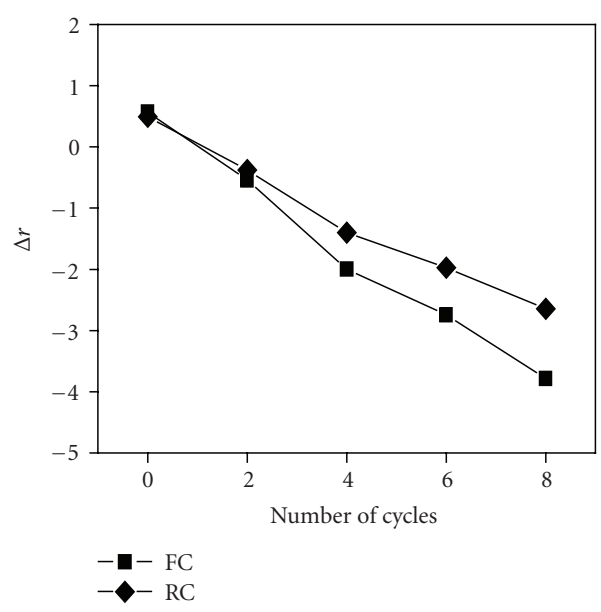

(b)

FIGURE 8: Coefficient of normal anisotrop $\langle r\rangle$ (a) and its variation $\Delta r$ (b) as a function of the number of cycles calculated with the FC and RC Taylor models. 
here are under way. It should be mentioned that similar calculations were already performed on rolled molybdenum sheets and stand in good agreement with the experimental results [25]. However, it may be remarked that small deviations of the calculated and measured mechanical parameters in [25] may be partly attributed to the effect of grain shape, latent hardening, and dislocation structure [26, 27], all of which have not yet been taken into account.

\section{ACKNOWLEDGMENT}

Thanks are due to T. Reiter for sample preparation.

\section{REFERENCES}

[1] R. Z. Valiev, Y. Estrin, Z. Horita, T. G. Langdon, M. J. Zechetbauer, and Y. T. Zhu, "Producing bulk ultrafine-grained materials by severe plastic deformation," Journal of the Minerals, Metals and Materials Society, vol. 58, no. 4, pp. 33-39, 2006.

[2] H. W. Höppel, J. May, and M. Göken, "Enhanced strength and ductility in ultrafine-grained aluminium produced by accumulative roll bonding," Advanced Engineering Materials, vol. 6, no. 9, pp. 781-784, 2004.

[3] W. Skrotzki, N. Scheerbaum, C.-G. Oertel, R. ArruffatMassion, S. Suwas, and L. S. Tóth, "Microstructure and texture gradient in copper deformed by equal channel angular pressing," Acta Materialia, vol. 55, no. 6, pp. 2013-2024, 2007.

[4] Y. Saito, H. Utsunomiya, N. Tsuji, and T. Sakai, "Novel ultrahigh straining process for bulk materials-development of the accumulative roll-bonding (ARB) process," Acta Materialia, vol. 47, no. 2, pp. 579-583, 1999.

[5] N. Tsuji, Y. Saito, H. Utsunomiya, and S. Tanigawa, "Ultrafine grained bulk steel produced by accumulative roll-bonding (ARB) process," Scripta Materialia, vol. 40, no. 7, pp. 795-800, 1999.

[6] I. Topic, H. W. Höppel, and M. Göken, "Deformation behaviour, microstructure and processing of accumulative roll bonded aluminium alloy AA6016," International Journal of Materials Research, vol. 98, no. 4, pp. 320-324, 2007.

[7] X. Huang, N. Tsuji, N. Hansen, and Y. Minamino, "Microstructural evolution during accumulative roll-bonding of commercial purity aluminum," Materials Science and Engineering A, vol. 340, no. 1-2, pp. 265-271, 2003.

[8] M. Dahms and H. J. Bunge, "The iterative series-expansion method for quantitative texture analysis-I: general outline," Journal of Applied Crystallography, vol. 22, part 5, pp. 439-447, 1989.

[9] M. Dahms and T. Eschner, Quantitative Texturanalyse durch iterative Reihenzerlegung von Beugungs-Polfiguren (software manual), 1996.

[10] H.-J. Bunge, "Zur Darstellung allgemeiner Texturen," Zeitschrift für Metallkunde, vol. 56, pp. 872-874, 1965.

[11] J. F. W. Bishop and R. Hill, "A theory of the plastic distortion of a polycrystalline aggregate under combined stresses," Philosophical Magazine, vol. 42, pp. 414-417, 1951.

[12] J. F. W. Bishop and R. Hill, "A theoretical derivation of the plastic properties of a polycrystalline face-centred metal," Philosophical Magazine, vol. 42, pp. 1298-1307, 1951.

[13] W. F. Hosford, The Mechanics of Crystals and Textured Polycrystals, Oxford University Press, Oxford, UK, 1993.

[14] P. Van Houtte, "A comprehensive mathematical formulation of an extended Taylor-Bishop-Hill model featuring relaxed con- straints," Textures and Microstructures, vol. 8-9, pp. 313-350, 1988.

[15] W. F. Hosford and W. A. Backofen, "Strength and plasticity of textured metals," in Fundamentals of Deformation Processing, pp. 259-292, Syracuse University Press, Syracuse, NY, USA, 1964.

[16] H. J. Bunge, "Some applications of the Taylor theory of polycrystal plasticity," Kristall und Technik, vol. 5, no. 1, pp. 145175, 1970.

[17] P. Van Houtte, "Treatment of elastic and plastic anisotropy of polycrystalline materials with texture," in Texture and Anisotropy of Polycrystals, vol. 273-275 of Materials Science Forum, pp. 67-76, Trans Tech Publications, Zurich, Switzerland, 1998.

[18] W. Skrotzki, R. Tamm, C.-G. Oertel, B. Beckers, H.G. Brokmeier, and E. Rybacki, "Texture induced plastic anisotropy of NiAl polycrystals," Materials Science and Engineering A, vol. 319-321, pp. 364-367, 2001.

[19] M. Heilmaier, M. Nganbe, B. Beckers, et al., "Plastic anisotropy of textured ODS nickel-base alloy PM 1000," Materials Science and Engineering A, vol. 319-321, pp. 290-293, 2001.

[20] G. I. Taylor, "Plastic strain in metals," Journal of the Institute of Metals, vol. 62, pp. 307-324, 1938.

[21] J.-J. Park, "Predictions of texture and plastic anisotropy developed by mechanical deformation in aluminum sheet," Journal of Materials Processing Technology, vol. 87, no. 1-3, pp. 146153, 1999.

[22] N. Q. Chinh, P. Szommer, Z. Horita, and T. G. Langdon, "Experimental evidence for grain-boundary sliding in ultrafinegrained aluminum processed by severe plastic deformation," Advanced Materials, vol. 18, no. 1, pp. 34-39, 2006.

[23] N. Q. Chinh, P. Szommer, T. Csanádi, and T. G. Langdon, "Flow processes at low temperatures in ultrafine-grained aluminum," Materials Science and Engineering A, vol. 434, no. 1-2, pp. 326-334, 2006.

[24] I. Topic, H. W. Höppel, M. Göken, D. Staud, M. Merklein, and M. Geiger, to appear in Materials Science and Engineering A.

[25] C.-G. Oertel, I. Hünsche, W. Skrotzki, W. Knabl, A. Lorich, and J. Resch, to appear in Materials Science and Engineering A.

[26] Z. J. Li, G. Winther, and N. Hansen, "Anisotropy in rolled metals induced by dislocation structure," Acta Materialia, vol. 54, no. 2, pp. 401-410, 2006.

[27] G. Winther, D. Juul-Jensen, and N. Hansen, "Modelling flow stress anisotropy caused by deformation induced dislocation boundaries," Acta Materialia, vol. 45, no. 6, pp. 2455-2465, 1997. 